Moraes, W.V.; Ribeiro, G.A. Indicadores para a identidade do turismo de base comunitária no território da Serra do Brigadeiro (MG). Revista Brasileira de Ecoturismo, São Paulo, v.6, n.1, jan/abr-2013, pp.107-122.

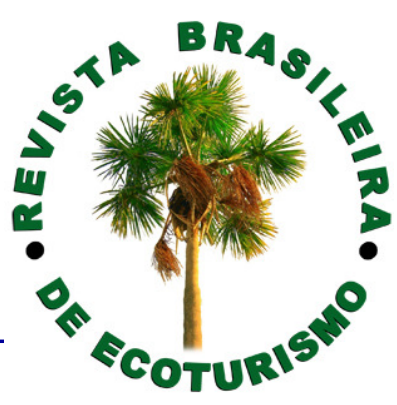

\title{
Indicadores para a identidade do turismo de base comunitária no território da Serra do Brigadeiro (MG)
}

\author{
Indicators for the identity of the community-based tourism on Serra do \\ Brigadeiro territory (MG, Brazil)
}

Werter Valentim Moraes, Guido Assunção Ribeiro

\section{RESUMO}

O presente trabalho é fruto do desenvolvimento de parte do Projeto Boas Práticas do Território da Serra do Brigadeiro, apoiado pelo Ministério do Turismo cujo objetivo foi ordenar os atrativos enquanto produto turístico de base comunitária. As Boas Práticas referem- se à concretização de núcleos de turismo de base comunitária estabelecidos em 5 regiões do entorno do Território da Serra do Brigadeiro, onde se insere o Parque Estadual da Serra do Brigadeiro - PESB, estado de Minas Gerais. O Núcleo do Boné, por ser o único limítrofe à unidade de conservação, vem se destacando na gestão do turismo de base comunitária. O Núcleo é organizado por quatro famílias parentes que desenvolvem: a hospedagem domiciliar de montanha, uma área de camping, a guiagem e a utilização de um pequeno restaurante rural. Os parâmetros pesquisados como atrativos foram: unidade de conservação, água, mata, cultura, espaço de convivência, produção associada ao turismo e hospitalidade. Seus principais indicadores foram: potencial de atratividade, grau de uso atual, representatividade, apoio comunitário local, estado de conservação da paisagem, infraestrutura e acesso. A identidade reconhecida no núcleo de turismo de base comunitária do Boné foi a produção associada ao turismo com os saberes e fazeres da família agricultora, a hospitalidade retratando a ruralidade, a cultura das festas fomentando grupos folclóricos, a mata e água com suas paisagens ainda selvagem e os espaços de convivência possibilitando uma interação entre turistas e anfitriões. Estas atividades propiciam uma experiência enriquecedora com o turismo de base comunitária.

PALAVRAS-CHAVE: Turismo de Base Comunitária; Atrativos; Identidade. 


\begin{abstract}
This work is the result of the development of the Project Planning Practice Sierra Brigadier, supported by Ministry of Tourism, whose objective was to order the appeal as community-based tourism product. The Good Practice relate to the achievement of core community-based tourism established in five regions around the territory of Sierra Brigadier, which includes the State Park of Sierra Brigadier - PESB, state of Minas Gerais. The Core Boné, as the only country bordering the conservation area, has been highlighted in the management of community-based tourism. The Center is organized by four families who develop relatives: a mountain home hosting, the camping area, the guidance and use of a small rural restaurant. The parameters studied were as attractive: the conservation area, water, forest, culture, living space, production linked to the tourism and hospitality. Its main indicators were potential attractiveness, level of current use, representation, support the local community, state of conservation of landscape, infrastructure and access. The identity were recognized in the core activities that are associated with the production of tourism with the knowledge and practices of the farm family, depicting the rural hospitality, festivals promoting the culture of folk groups, the forest and water depicting a still wild scenic beauty, the living space allowing coexistence between tourists and hosts. These activities provide an enriching experience with community-based tourism. The production associated with tourism was the identity recognized in the core of the community-based tourism Boné, including the knowledge and practices of the farm family, hospitality that showing rurality, the cultural festivals that foster folk groups, the woods and water with its landscapes still wild and living spaces allowing for interaction between tourists and hosts.
\end{abstract}

KEYWORDS: Community-Based Tourism; Attractions; Identity.

\title{
Introdução
}

O turismo na agricultura familiar pode complementar a renda com a comercialização de produtos e serviços diretamente ao visitante dentro da propriedade rural. Diante desse cenário, o turismo possibilita a valorização da família agricultora, uma vez que a sua cultura torna-se o próprio atrativo turístico, com efeitos diretos no aumento da auto-estima da população.

O turismo no meio rural da agricultura familiar propõe o uso racional dos recursos naturais, sua preservação, conservação e recuperação, visto que estes recursos passam a serem atrativos turísticos (BRASIL, 2003).

Segundo o plano de desenvolvimento territorial da Serra do Brigadeiro (CTAZM, (Centro de Tecnologias Alternativas - Zona da Mata, 2004), o turismo rural foi definido como um dos eixos estratégicos de ação nas comunidades do entorno do Parque Estadual da Serra do Brigadeiro, que pretende explorar o potencial turístico da referida unidade de conservação e do território de maneira a promover a qualidade de vida das comunidades, sem, no entanto, descaracterizá-las e/ou desrespeitá-las. 
O objetivo do presente trabalho foi identificar por meio de indicadores, as atividades turísticas desenvolvidas no núcleo do Boné, com o intuito de reconhecer os atrativos de turismo de base comunitária que são a identidade turística do Território da Serra do Brigadeiro.

\section{Uma nova ordem para o turismo}

A idéia de potencialidade se apresenta comumente na bibliografia turística. Tem-se, que a popularização do termo "potencial turístico" ocorre pela falta de conceitos mais precisos dessa expressão e da pouca possibilidade de se avaliar de forma clara esse "potencial" com os métodos e instrumentos até agora criados para tal finalidade.

Nesse sentido, Matheus (2003) e Almeida (2006), citam a importância de se conhecer a realidade quanto ao potencial turístico, ao detectar que a ótica errada deste potencial pode resultar em impactos negativos para o meio ambiente.

Com esta ótica, estudos sobre indicadores são utilizados como uma das técnicas para se conhecer, de fato, o estágio em que se encontram os produtos e serviços turísticos. Filetto (2009) e Costa (2010) em estudos recentes sobre indicadores constatam o seu poder de sintetizar conjuntos complexos de informações turísticas, e, apresentar significados relevantes dos aspectos analisados.

O Programa de Redução da Pobreza pela Exportação - PRPE (Export-Led Poverty Reduction Programme - EPRP), do International Trade Center - ITC (Centro de Comércio Internacional) também utiliza indicadores na perspectiva de monitorar a capacidade empreendedora de produtores e prestadores de serviços nas comunidades (UNCTAD/WTO, 2005). O objetivo final do PRPE é aumentar o nível de vida das comunidades tradicionais desfavorecidas, tendo por objetivo o aumento da qualidade e da quantidade da produção e dos serviços oferecidos pelas mesmas, ao passo que responde às necessidades dos principais mercados internacionais e nacionais.

Segundo Maldonado (2009), a finalidade da empresa comunitária não é lucro nem a apropriação individual dos benefícios que são gerados, e sim a sua distribuição equitativa, por meio do investimento em projetos de caráter social ou de produção.

Com base nessas premissas e com o intuito de responder a questionamentos, as Entidades do CEPEC (Centro de Pesquisa e promoção Cultural) e da Associação dos Amigos de Iracambi tomaram a iniciativa de associarem-se para desenvolver uma proposta de turismo responsável para aproveitar o potencial turístico do Território da Serra do Brigadeiro buscando apoio á REDE TRAF - Turismo Rural na Agricultura familiar e à REDE TURISOL - Turismo Solidário. De acordo com a realidade desta iniciativa turística, a proposta leva a um planejamento e gestão comprometidos com trabaIhos em rede.

Para Benevides (2002), a viabilidade de realizar o desenvolvimento local por meio do turismo dependeria da equalização de cinco objetivos: preservação/conservação ambiental; manutenção da identidade cultural; geração de ocupações produtivas de renda; de- 
senvolvimento participativo; e, qualidade de vida. Assim, a identificação de atrativos e seus indicadores compatíveis com estes objetivos subsidia o planejamento para a valorização a identidade turística do Território da Serra do Brigadeiro.

$\mathrm{Na}$ atualidade o turismo "responsável-sustentável" vem se tornando um termo usual, no entanto, sua prática ainda não está sendo perfeitamente realizada pelos consumidores e fornecedores da atividade. Com o intuito de implementar melhor consciência sobre a atividade, perante à sociedade, o turismo responsável é apresentado como: não massificado; respeita a cultura local e patrimonial; gerenciado pela própria comunidade local para garantir desenvolvimento socioeconômico; baseia-se na aprendizagem intercultural entre turistas e população local (ALTER NATIVAS, 2009).

O Programa Nacional de Fortalecimento da Agricultura Familiar - Pronaf, define turismo rural na agricultura familiar, entendido como "a atividade turística que ocorre na unidade de produção dos agricultores familiares que mantêm as atividades econômicas típicas da agricultura familiar, dispostos a valorizar, respeitar e compartilhar seu modo de vida, o patrimônio cultural e natural, ofertando produtos e serviços de qualidade e proporcionando bem estar aos envolvidos" (Brasil, 2003).

A realidade turística da Serra do Brigadeiro, muito se assemelha com o Turismo Baseado na Comunidade - TBC apresentado pelo UNCTAD/WTO (2005) reconhecido em Catmandu, no Nepal, como uma oportunidade de interação entre anfitriões e hóspedes trazendo benefícios diretos para ambos e indiretos para o meio ambiente local. Esta semelhança se justifica na Serra do Brigadeiro com as várias ações locais na busca de uma organização da atividade, por iniciativas protagonizadas dos empreendedores agricultores familiares em oferecer vivências das práticas rurais em suas lavouras de café.

A definição do TBC pelo WWF (2001) complementa a anterior no sentido de reforçar que este envolvimento deve resultar em melhorias de qualidade de vida destes envolvidos por meio do controle efetivo sobre o desenvolvimento e gestão desta nova atividade turística. E por meio do envolvimento participativo desde o início, projetos de turismo devem proporcionar a maior parte de seus benefícios para as comunidades locais.

A Rede TURISOL, define turismo comunitário como "a atividade turística que apresenta gestão coletiva, transparência no uso e destinação dos recursos e na qual a principal atração turística é o modo de vida da população local. Nesse tipo de turismo a comunidade é proprietária dos empreendimentos turísticos e há a preocupação em minimizar o impacto ambiental e fortalecer ações de conservação da natureza" (PROJETO BAGAGEM, 2010, p.36).

O turismo comunitário é uma estratégia para que populações tradicionais, independente do grau de descaracterização, frente à hegemonia das sociedades urbanas industriais, sejam protagonistas de seus modos de vida próprios, tornando-se uma alternativa possível ao modo de vida materialista-consumista (SAMPAIO, 2005). Essas comunidades são definidas por critérios geográficos, como um território isolado; culturais, compartilhando costumes, usos e tradições; ou por funções socioeconômicas, variando por modos de pro- 
dução e distribuição (BARRETO, 2004). Tais comunidades, mesmo que ainda possuam grau de descaracterização,permite encontrar no seu âmbito o principal atrativo do turismo comunitário que é o compartilhamento solidário do dia a dia. A convivência é uma relação social de interesse mútuo, prima pelo diferente, pela autenticidade no seu jeito de falar, cantar, dançar, comer, entre outros, respeita a simplicidade existente nas comunidades tradicionais.

\section{Indicadores com a aplicabilidade no turismo}

Os indicadores de sustentabilidade começaram a serem desenvolvidos a partir dos anos 1980, de acordo com a definição de desenvolvimento sustentável existente no relatório Bruntland. Atualmente, inúmeros organismos governamentais, nãogovernamentais, institutos de pesquisa e universidades fazem uso de indicadores de sustentabilidade. Em nível internacional podem-se citar órgãos que fazem uso de indicadores de sustentabilidade, entre outros, a Organização para a Cooperação e Desenvolvimento Econômico (OCDE), o Programa das Nações Unidas para o Meio Ambiente (PNUMA) e o governo francês (MAGALHÃES, 2007).

De acordo com Cerro (1993), a natureza diversa e com frequência intangível dos recursos turísticos, unida à inevitável carga de subjetividade que é tolerada em toda valoração estética, tem dificultado enormemente a elaboração de uma metodologia de aplicação universal que permita uma valoração racional e sistemática destes tipos de recursos.

Segundo o IBGE (2008) indicadores são ferramentas constituídas por uma ou mais variáveis que, associadas através de diversas formas, revelam significados mais amplos sobre os fenômenos a que se referem. As medidas devem evidenciar mudanças que ocorrem em uma dada realidade, principalmente pela ação do homem.

Os indicadores devem nortear as decisões do poder público, bem como da iniciativa privada, no planejamento das ações, assim como no monitoramento das transformações territoriais que serão impingidas no espaço (COSTA, 2010).

Encontradas na literatura científica, duas citações que merecem destaque, a de Marzall e Almeida (2005, p.48) apresentando o indicador como: "uma ferramenta que permite a obtenção de informações sobre uma dada realidade"; e a de MITCHELL (1995) apresentando como sua principal característica a de "poder sintetizar um conjunto complexo de informações, retendo apenas o significado essencial dos aspectos analisados".

Os indicadores podem ser tão variados quanto os fenômenos considerados, provêm de diferentes fontes e possuem três funções básicas - quantificação, simplificação da informação e comunicação. Desta forma, são capazes de contribuir à percepção dos progressos alcançados e despertar a consciência da população $(\mathrm{PERH}$, 2005). 


\section{Caracterização da Área de Estudo}

A área geográfica da pesquisa compreende o município de Araponga, inserido no Território da Serra do Brigadeiro estabelecido dentro dos princípios da política pública do Ministério do Desenvolvimento Agrário (MDA), no qual o Parque Estadual da Serra do Brigadeiro está localizado.

No Território da Serra do Brigadeiro predominam pequenas propriedades agrícolas, com produção familiar com reduzida assistência técnica e baixo acesso à tecnologia. $\mathrm{O}$ relevo da região, com declives acentuados, é impróprio para a pecuária, resultando em baixa produtividade. A pequena oferta de atividades industriais e serviços e a dificuldade para absorver o excedente de mão-de-obra agrícola, gera um intenso fluxo migratório, em especial no meio rural, tanto interno como externo à região. A atuação de diferentes instituições educacionais no Território é marcante. Dentre as federais, destaca-se a UFV (Universidade Federal de Viçosa), que ali promove atividades de ensino, pesquisa e extensão. Destacam-se ações pontuais da FEAM (Fundação Estadual do Meio Ambiente), especialmente quanto a processos de licenciamento de atividades mineradoras, além da presença da UEMG (Universidade do Estado de Minas Gerais), por intermédio da Fundação FAFILE (Faculdade de Filosofia, Ciências e Letras) de Carangola.

O Parque Estadual da Serra do Brigadeiro - PESB, criado em 27 de setembro de 1996 pelo decreto número 38.319; localiza-se na Zona da Mata Mineira a $290 \mathrm{~km}$ de distância de Belo Horizonte e ocupa parte dos municípios de Ervália, Fervedouro, Sericita, Araponga, Miradouro, Pedra Bonita, Muriaé e Divino.. Está situado entre as divisas das microrregiões de Viçosa, Muriaé, Manhuaçu e Ponte Nova, entre os meri-

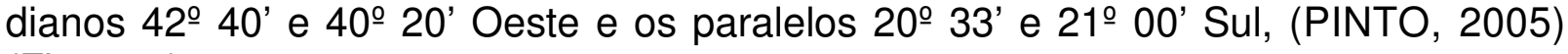
(Figura 1)

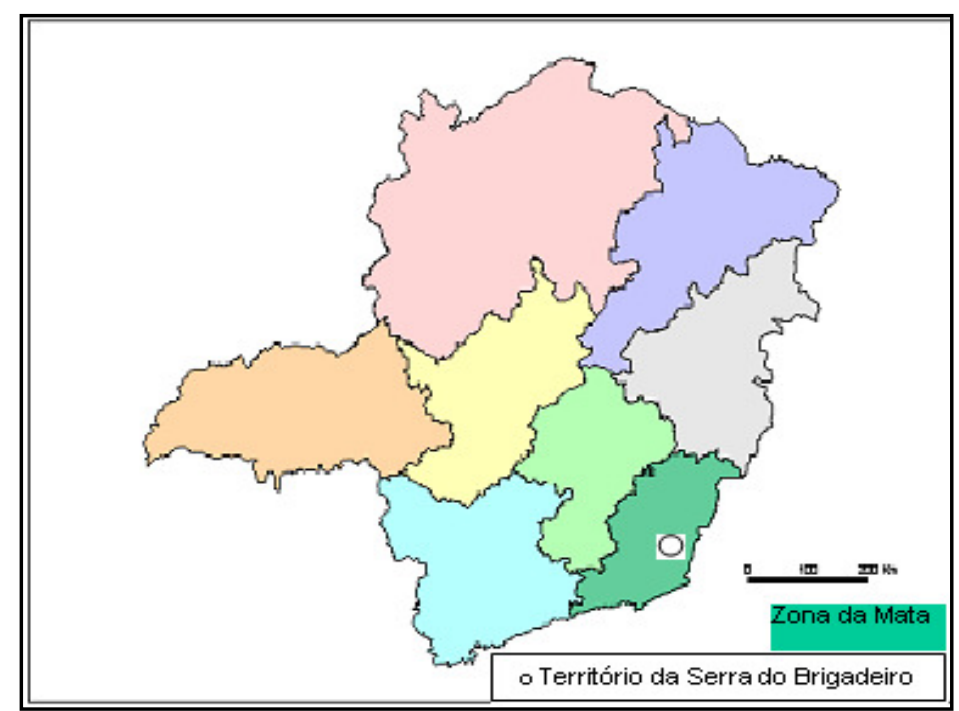

Figura 1: Localização da Serra do Brigadeiro no Estado de Minas Gerais. Fonte: autores.

Figure 1: Location of the Serra do Brigadeiro State of Minas Gerais. Source: authors. 
Com uma área total de 13.210 ha, o PESB representa um dos últimos fragmentos da Mata Atlântica com grande extensão de florestas contínuas do Estado de Minas Gerais. Situa-se entre os picos rochosos de um prolongamento das Serras da Mantiqueira e Caparaó, abrigando espécies endêmicas. O acesso mais utilizado para a sede do Parque é pela cidade de Araponga. Saindo de Belo Horizonte o visitante deve seguir pela BR 040, no sentido do Rio de Janeiro, até a BR 356. Seguir pela MG 262 até Ponte Nova, pegar a BR 120, sentido Viçosa. De Viçosa, até Araponga pela MG. 482 e mais $11 \mathrm{~km}$ da Estrada Parque até a sua portaria. As distâncias da sede do Parque até as capitais do sudeste brasileiro são mostradas na Tabela 1, (PINTO, 2005).

Tabela 1: Relação das distâncias entre a sede do PESB em Araponga e as capitais do sudeste brasileiro. Table 1: List of distances between headquarters of PESB in Araponga in the capital of southeastern Brazil.

\begin{tabular}{|c|c|c|}
\hline Origem & Destino & Distancia \\
\hline Araponga & Belo Horizonte & $193 \mathrm{~km}$ \\
\hline Araponga & São Paulo & $680 \mathrm{~km}$ \\
\hline Araponga & Rio de Janeiro & $293 \mathrm{~km}$ \\
\hline Araponga & Vitória & $373 \mathrm{~km}$ \\
\hline
\end{tabular}

Fonte: www.abcr.org.br, acesso em agosto de 2010.

Source: www.abcr.org.br, access in August 2010.

Araponga teve o primeiro nome de São Miguel das Almas dos Arrepiados que surgiu no Ciclo do Ouro, em 1781, quando D. Rodrigo José de Menezes, governador da Capitania de Minas, visitou a região e distribuiu sesmarias e áreas de mineração. Com o tempo, os veios auríferos se esgotaram e o crescimento do povoado tornou-se mais lento. Mas, em 1826, foi criada a freguesia de São Miguel e Almas dos Arrepiados, tornando-se São Miguel do Araponga, em 1857, quando foi elevado a distrito. Em 1938, com o Estado Novo, seu nome foi simplificado, para em 1962 tornar-se cidade. Em Araponga encontram-se a Pedra Redonda, patrimônio ecológico, a imagem do Bom Jesus e a igreja matriz de São Miguel Arcanjo, patrimônios históricos do município. Atualmente o município vem se destacando como pólo turístico regional com alguns empreendimentos de hospedagem como mostra a tabela 2.

Tabela 2 - Empreendimentos turísticos do entorno do PESB no município de Araponga (MG).

Table 2: Enterprise Touristic around of PESB in Araponga City (MG, Brazil).

\begin{tabular}{|c|c|c|c|}
\hline Empreendimento & Leitos & Lixo & Localização \\
\hline Pousada Serra D'água & 30 & $\begin{array}{c}\text { Compostagem, fossa sépti- } \\
\text { ca com filtro }\end{array}$ & Zona rural de Araponga \\
\hline $\begin{array}{c}\text { Pensão e Restaurante } \\
\text { Santa Maria }\end{array}$ & 18 & - & $\begin{array}{c}\text { Zona urbana de Arapon- } \\
\text { ga }\end{array}$ \\
\hline Pousada Vale da Lua & 35 & $\begin{array}{c}\text { Fossas com caixa séptica. } \\
\text { Lixo sólido vai para o lixão. }\end{array}$ & $\begin{array}{c}\text { Zona rural de Araponga, } \\
\text { Serra do Boné }\end{array}$ \\
\hline Pousada do Remanso & 20 & - & $\begin{array}{c}\text { Zona rural de Araponga, } \\
\text { Sitio Córrego do Boné }\end{array}$ \\
\hline
\end{tabular}

Fonte: Pinto (2005).

Sopurce: Pinto (2005). 


\section{O Projeto Boas Práticas de Turismo de Base Comunitária}

Os dados necessários sobre os atrativos de turismo de base comunitária foram obtidos a partir do Projeto Boas Práticas de turismo de base comunitária, que desenvolveu as seguintes ações:

1. Seleção das famílias a serem envolvidas no Programa.

As famílias foram escolhidas a partir de questionários e entrevistas. Um banco de dados foi criado para monitorar as informações obtidas sobre as famílias, permitindo uma intervenção mais realista e com foco nos princípios do turismo de base comunitária.

2. Desenvolvimento do plano de ação de turismo para cada família.

O plano de ação, construído por meio do Diagnóstico Rápido Participativo DRP, utilizando as técnicas de calendário sazonal, o mapa e o diagrama de fluxo, possibilitou visualizar as ações a serem implementadas para se diversificar a renda familiar. Neste plano, discutiram-se como os recursos existentes em cada propriedade rural, poderiam ser transformados em produtos turísticos, os possíveis riscos que a atividade poderá trazer e as estratégias de ação para minimizá-los. Nesta etapa reconheceram-se as necessidades de capacitação em gerenciamento de empreendimentos de turismo rural e ecoturismo. Foi realizado quatro oficinas de 16 horas cada, nos municípios abrangidos pelo projeto abordando os temas sobre artesanato, bioconstrução (2) e condução ambiental.

\section{Visitas técnicas.}

Foram realizadas visitas às experiências do turismo solidário existente no Vale do Jequitinhonha (Estado de Minas Gerais) e de turismo rural na agricultura familiar, do Projeto Acolhida na Colônia (Estado de Santa Catarina). O objetivo foi fortalecer os laços do turismo de base comunitária aumentando a área de abrangência deste turismo responsável.

\section{Produção de um catálogo de produtos e serviços.}

Foi elaborado o catálogo dos produtos e serviços turísticos dentro dos princípios do Turismo de Base Comunitária servindo como ferramenta de comercialização e divulgação.

\section{Realização de encontros de Turismo com Base Comunitária.}

Os encontros serviram para buscar uma integração na operacionalização das ações de forma coletiva, possibilitando uma interação entre as lideranças comunitárias e as instituições parceiras.

6. Elaboração e implantação da sinalização turística para o Projeto.

Foram sinalizados os pontos de: comercialização, como: entreposto; produção; atividade de lazer e recreação, com ícones personalizados do programa, indicando distancias, direção e nome do empreendimento rural, com base na sinalização turística do Ministério do Turismo. 
Moraes, W.V.; Ribeiro, G.A.

\section{Elaboração de estratégias de comercialização.}

A realização de um pequeno fantur ocorreu para os membros da REDE TRAF e da REDE TURISOL conhecem o projeto e um site foi desenvolvido para divulgar as informações sobre o turismo de base comunitária no Território da Serra do Brigadeiro.

\section{Metodologia}

Foram acompanhadas as seis ações citadas anteriormente, com base na pesquisa ação (HAGUETE, 2003), do projeto Boas Práticas de Turismo de Base Comunitária com o intuito de agrupar as propriedades rurais em núcleos para identificar os atrativos passíveis de serem transformados em produtos turísticos. Este acompanhamento permitiu elaborar um banco de dados que subsidiou a utilização de indicadores como ferramenta para identificar a identidade turística local.

Para a identificação dos atrativos de turismo de base comunitária, seguiu-se o mapeamento de Sansolo e Bursztyn (2009). Tais atrativos foram conceituados e ajustados conforme realidade diagnosticada no Território da Serra do Brigadeiro, sendo:

- Unidade de Conservação: expressa a existência de áreas protegidas, neste caso o Parque Estadual da Serra do Brigadeiro e suas relações com as comunidades envolvidas com o turismo de base comunitária;

- Água: expressa a presença do referido recurso natural disponível para atividades interativas de lazer e recreação voltados para o turismo de base comunitária onde acontecem relações ambientais, sociais e culturais;

- Mata: expressa a presença do referido recurso natural em condições de ser utilizado pela comunidade por meio de atividades interativas de lazer e recreação voltadas para o turismo de base comunitária, onde acontecem relações ambientais, sociais e culturais;

- Cultura: expressa a presença de bens localizados nos sítios turísticos que contem determinadas características peculiares relacionadas a aspectos arquitetônico, histórico, cultural, folclórico e sócio-econômico, em condições de serem utilizados por meio de atividades de lazer e recreação voltados para o turismo de base comunitária;

- Espaço de convivência: são locais peculiares que a comunidade compartilha suas experiências diárias no meio rural como a venda, o bar, a praça, a sombra da árvore, a varanda da casa, entre outros, na mesma região frequentada conjuntamente por turistas e residentes onde pode haver recreação e lazer com a comunidade e os turistas;

- Produção associada ao turismo: é toda e qualquer produção artesanal e agropecuária que detém atributos naturais e/ou culturais de uma determinada localidade ou região capazes de agregar valor turístico aos sitios turísticos por meio de trocas de saberes e fazeres, com a participação na rotina da propriedade em sua lida no meio rural. 
- Hospitalidade: refere-se a relação peculiar entre hospedeiro e hóspede por meio de vivências compartilhadas, sendo manifestada a dinâmica do dom na convivência entre indivíduos que pertencem a sociedades e culturas diferentes.

Para a avaliação dos atrativos, segundo a metodologia de hierarquização de atrativos turísticos do Programa de Regionalização Turística do Brasil, (CICATUR Brasil, 2005), foram considerados os seguintes indicadores, que também foram ajustados de acordo com a realidade da região objeto de estudo:

- Grau de uso atual: permite analisar o atual volume de fluxo turístico efetivo e sua importância para o município. Difere do grau de interesse por representar a situação atual, em vez da potencial. Um alto grau de uso indica que o atrativo apresenta uma utilização turística efetiva.

- Representatividade: fundamenta-se na singularidade ou raridade do atrativo. Quanto mais se assemelhar a outros atrativos, menos interessante ou prioritário.

- Apoio local e comunitário: a partir da opinião dos líderes comunitários, devese analisar o grau de interesse da comunidade local para o desenvolvimento e disponibilidade ao público.

- Estado de conservação da paisagem circundante: verificar, por observação in loco, o estado de conservação da paisagem que circunda o atrativo. Neste item é analisada a ambiência do atrativo.

- Infraestrutura: verificar, in loco, se existe infra-estrutura disponível no atrativo e o seu estado.

- Acesso: verificar as vias de acesso existentes e suas condições de uso.

Cada atrativo foi analisado pelo conjunto dos indicadores. Estes indicadores permitiram reconhecer em cada atrativo a relação do mesmo com a comunidade local. Esta relação foi entendida como a gestão da atividade de turismo de base comunitária no Território da Serra do Brigadeiro, passível de ser transformado em produto turístico.

\section{Principais resultados e discussão}

As famílias selecionadas para participarem do projeto apresentaram duas características básicas, que foram os requisitos que as credenciaram. A primeira foi ter produtos a serem comercializados com base na proposta da economia solidária. A segunda característica foi ter estrutura para alguma vivência com a atividade.

No núcleo de turismo de base comunitária do Boné estão envolvidas 4 famílias de agricultores que também são parentes entre si. Cultivam o café, com uma estrutura com máquina de limpar café, armazém e trator. Na estrutura turística apresentam um restauranate familiar, dois módulos de hospedagem com 3 quartos com 2 camas em cada quarto, oferecendo 12 leitos. Oferecem área de camping com sanitários e ba- 
nheiros. No núcleo se localiza a caminhada até o Pico do Boné com 1635 metros de altitude, sendo a mais pitoresca do interior do Parque, além da trilha do carvão de maior tamanho. Como atrativos existe várias cachoeiras, além de poder ser vivenciados as atividades realizdas na casa de forno, onde se produz os quitutes e quitandas, um curral com leite ao pé da vaca, uma pescaria tradicional noturna de cambeva com parão e um passeio de trator pela comunidade e a apresentação da folia de reis do Boné. Este núcleo credenciado também no programa de economia solidária fica no município de Araponga, a $15 \mathrm{~km}$ da sede.

No núcleo do Boné localiza-se na região onde ocorre considerável fluxo de visitação por causa da trilha que dá acesso ao pico do Boné, atrativo que se encontra no interior do PESB. Este fato estabelece ao parâmetro "unidade de conservação" o reconhecimento do potencial de atratividade devido aos recursos hídricos, faunísticos e florísticos lá existentes.

A "água" é um atrativo bastante requisitado pelos turistas em geral. Neste núcleo existem cachoeiras com piscinas naturais que podem ser aproveitadas, tanto no interior do PESB como no núcleo.

A "mata" é outro parâmetro que agrega valor à atividade turística enquanto atrativo, mas ainda pode ser melhor aproveitada pelos integrantes do núcleo. As trilhas exploradas na região limitam-se à do Pico do Boné e à Gruta do Ouro, sendo que existem várias outras que podem ser exploradas, enquanto atividade ecoturística, pela comunidade e turistas.

A "cultura" pode ser considerada como produto turístico de base comunitária devido a existência do grupo folia de reis do Boné, que vem se apresentando para visitantes e turistas do núcleo. Esta experiência de mostrar a cultura local enquanto atrativo é representativa e com o apoio comunitário vem obtendo interação dos visitantes nos saberes e fazeres locais.

Um dos casos mais conhecidos e estudados de turismo comunitário brasileiro é o da Prainha de Canto Verde, no litoral do Ceará. Neste local, o planejamento da atividade teve início em 1994, por meio da construção do Projeto Turístico Socialmente Responsável, valendo-se do planejamento participativo e descentralizado (ZECHNER, et al. 2008). Esta proposta de planejamento é a que se pretende desenvolver neste núcleo.

Para caracterizar o "espaço de convivência", existe um restaurante familiar, com bar em anexo, onde ocorrem confraternizações apoiadas pela comunidade local. No ambiente pode-se jogar sinuca, baralho e ouvir "causos" da região,contados pelos moradores locais.

A "produção associada ao turismo" mostrou que a alimentação servida na pousada e no restaurante deve utilizar melhor os produtos dos próprios quintais, inclusive a carne. $O$ artesanato de palha de café, estimulado pelo CEPEC, vem sendo comercializado, sensibilizando os turistas e a comunidade como consumidores, incentivando mais uma fonte de renda. 
A experiência do núcleo com o artesanato da palha de café é promissora, mas, ainda incipiente. Ela é similar às experiências do projeto Ação Comunitária do Brasil que existe há 40 anos. Neste sentido, a gama de possibilidades, para trocar experiências desta natureza, pode levar o núcleo a uma melhor visibilidade fora da região. Este tipo de troca pode ser realizada com o projeto Ação Comunitária, que trabalha o intercâmbio com artistas africanos a fim de enriquecer os processos e produtos desenvolvidos nas favelas do Rio de Janeiro, nas áreas de moda, gastronomia e apresentações artísticas (BRASIL, 2010). Este projeto está entre os que o Ministério do Turismo apóia, assim como o Projeto Boas Práticas de Turismo de Base Comunitária no Território da Serra do Brigadeiro.

A "hospitalidade" da Pousada Remanso, inaugurada em 1996, é pitoresca e caracterizada como empreendimento turístico pioneiro no entorno do PESB. A decoração simples reforçando a ruralidade nas hospedagens torna os ambientes mais aconchegantes agrega valor ao potencial de atratividade, o que acontece na Pousada Remanso no núcleo Boné.

Conforme interpretado, uma estratégia de aproveitamento dos atrativos, sob a ótica turística, pode ser melhor aproveitada para se obter êxito com a atividade turística neste núcleo, como ocorre na Fundação Casa Grande (Olinda - Pernambuco). A Fundação Casa Grande desenvolve um trabalho exemplar com jovens em Nova Olinda, com ênfase no turismo cultural, como uma escola de referência em gestão cultural com atividades formadoras em: comunicação social, artes cênicas, música e educação patrimonial. Estas atividades vêm estimulando um fluxo de visitantes para a hospedagem nas casas dos jovens que atuam na Fundação (BRASIL, 2010).

Segundo Marzall e Almeida (2005), os indicadores devem se relacionar entre si de modo a permitir uma análise destas relações para que seja representativo o resultado, por meio de um enfoque integrado. Esta característica está sendo bem retratada neste núcleo, com a cultura e o espaço de convivência.

A experiência turística deste núcleo é também muito semelhante ao Consórcio Cooperativo Rede Ecoturística Nacional - COOPRENA, na Costa Rica. Zechner et al. (2010) relatam a existência de uma comunidade, que tomou posse de mais de 500 hectares de uma multinacional e fundou a COPESILENCIO. As principais atividades realizadas foram a capacitação de famílias de agricultores, trabalho em rede e implantação do ecoturismo comunitário. A COPESILENCIO destacou-se na organização social, inserção das mulheres e jovens nos projetos desenvolvidos, preservação dos recursos naturais e resgate cultural. Como resultado na qualidade de vida, percebeu-se melhora da auto-estima das pessoas, participação ativa da comunidade na preservação dos recursos naturais e a articulação comunitária em redes de trabalho que primam pelas técnicas de produção tradicional. Este é um exemplo pode ser seguido para que a experiência deste núcleo do Boné se estenda aos demais núcleos de turismo de base comunitária do Território da Serra do Brigadeiro, enquanto resultado do trabaIho cooperativo. 
Moraes, W.V.; Ribeiro, G.A.

\section{Conclusões}

Nesta pesquisa, a identidade turística do núcleo do Boné foi demonstrada pelo atrativo da hospitalidade da família rural, quando é vivenciada sua cultura por meio de fazeres e saberes folclóricos, culinários e ecológico.

As famílias envolvidas neste núcleo conseguiram ser um catalisador da atividade turística para o Território da Serra do Brigadeiro, pois demonstraram ações articuladas ao projeto e deste com as redes TRAF e TURISOL. Esta relação foi a mola propulsora para a organização dos empreendedores familiares.

O trabalho familiar com a atividade turística demonstra peculiaridades envolvidas na gestão do empreendimento rural de base familiar resultando visibilidade local e regional, facilitando assim sua promoção e divulgação.

O núcleo estabelecido proporciona vários tipos de vivências relacionadas com os atrativos pesquisados. Para o visitante turista, estas relações comuns no meio rural, é trabalhado de forma inovadora e atraente para aqueles que procuram uma experiência enriquecedora de viagem.

Foi perceptível que os atrativos (parâmetros) e os indicadores estão em consonância com os preceitos da atividade de turismo de base comunitária, os quais vêm sendo trabalhados pela Rede Brasileira de Turismo Solidário - TURISOL e pela Rede de Turismo Rural na Agricultura Familiar - TRAF. Esta constatação ratifica a utilização de metodologias com indicadores para avaliar e monitorar também as atividades de turismo de base comunitária.

\section{Referências bibliográficas}

ALTERNATIVAS, Iniciativas Interculturales. Disponível em: http://www.reasnet.com/ nativas. Acessado em novembro de 2009:

ALMEIDA, M. Matriz de avaliação do potencial turístico de localidades receptoras. Tese de doutorado. Escola de Comunicação e Artes da Universidade de São Paulo. São Paulo, 2006. 234p.

BARRETTO, M.. Relações entre visitantes e visitados: um retrospecto dos estudos socioantropológicos. Turismo em Análise, São Paulo, v. 15, n. 2, p. 133-149, 2004.

BRASIL. Ministério do Turismo. Dinâmica e diversidade do turismo de base comunitária: desafio para a formulação de política pública. Ministério do Turismo. Brasília. 2010. 88p.

BRASIL. Ministério do Turismo.. Programa de regionalização do turismo; roteiros do Brasil; roteirização turística; módulo operacional 7. Brasília, 2005. 43p.

BRASIL. Ministério do Desenvolvimento Agrário. Programa de Turismo Rural na Agricultura Familiar. 2003, 89p. 
BENEVIDES, I.P. Para uma agenda de discussão do turismo como fator de desenvolvimento local. In: RODRIGUES, A.B. (Org.). Turismo e Desenvolvimento Local. 3 ed. São Paulo: Hucitec, 2002. p. 23-41.

COSTA, N. M. C. In: SEMINÁRIO LATINO-AMERICANO DE GEOGRAFIA FÍSICA, 6 , 2010, SEMINÁRIO IBERO-AMERICANO DE GEOGRAFIA FÍSICA, 2, Anais, 2010. Universidade de Coimbra.

COSTA, N. M. C. et al. Indicadores físico-bióticos de desenvolvimento sustentável do ecoturismo em áreas protegidas brasileiras. Disponível em: http:// www.uc.pt/fluc/cegot/VISLAGF/actas/tema5/nadja. Acesso em: dez 2010.

CTA - ZM. Centro de Tecnologias Alternativas da Zona da Mata. Plano Territorial Rural de Desenvolvimento Rural Sustentável - PTDRS Serra do Brigadeiro, 2004. Ministério do desenvolvimento Agrário, 2004, 81 p.

CERRO, F. L. Técnicas de evaluación del potencial turistico. Madrid: Ministério de Industria, Comercio y Turismo, 1993. 261p.

FILETTO, F. Desenvolvimento de indicadores de sustentabilidade para o ecoturismo em unidades de conservação. Tese de doutorado. Universidade Federal de lavras UFLA. 2009. 143p.

HAGUETTE, M. T. F. Metodologias qualitativas na sociologia. Petrópolis (RJ):Vozes; 2003. 92 p.

IBGE. Indicadores de desenvolvimento sustentável: Brasil 2008. IBGE, Coordenação de Recursos Naturais e Estudos Ambientais. Coordenação de Geografia. Rio de Janeiro: IBGE, Instituto Brasileiro de Geografia e Estatística, 2008. 479 p.

MALDONADO, C. O Turismo rural comunitário na América latina. In: BARTHOLO, R.; SANSOLO, D.G.; BURSZTYN, I. Turismo de Base Comunitária diversidade de oIhares e experiências brasileiras. Rio de Janeiro: Editora Letra e imagem, 2009, parte I, p.25-44.

MARZALL, K.; ALMEIDA, J. Indicadores de Sustentabilidade para Agroecossistemas Estado da arte, limites e potencialidades de uma nova ferramenta para avaliar o desenvolvimento sustentável. Cadernos de Ciência \& Tecnologia, Brasília, v.17, n.1, p.41- 59, jan./abr. 2000.

MAGALHÃES JR., Antônio Pereira. Indicadores ambientais e recursos hídricos: Realidade e perspectiva para o Brasil a partir da experiência francesa. Rio de Janeiro: Bertrand Brasil, 2007.

MATHEUS, Z. M. A. Gestão e avaliação de programas - Estudo de Caso: Programa Nacional de Municipalização do Turismo - PNMT. Tese (Doutorado) - Escola de Comunicações e Artes, Universidade de São Paulo, São Paulo, SP 2003. 134p.

MITCHELL, G.; MAY, A.; McDONALD, A.P. A Matthodological Framework for the Development of indicators. International Journal of Sustainaible of development 
Moraes, W.V.; Ribeiro, G.A.

and word Ecology, 2, 104-123. 1995.

PROJETO BAGAGEM. Série TURISOL de Metodologias: Parte 2 - Projeto Bagagem. 42p. 2010. Disponível em: http://www.turisol.org.br/wp/wp-content/ uploads/2011/02/Livreto-p bagagem-09-parte2-2.pdf. Acessado em janeiro de 2011.

PINTO, F. Q. B. Avaliação do Ecoturismo em três municípios do entorno do parque Estadual da Serra do Brigadeiro (PESB) - MG. 2005. 125p. Dissertação (Mestrado em Ciência Florestal) - Universidade Federal de Viçosa. Viçosa, MG, 2005.

PERH - Plano Estadual de Recursos Hídrico, 2004-2007 (2005). Secretaria de Energia, Recursos Hídricos e Saneamento, Departamento de Águas e Energia Elétrica. Disponível em: <http://www.sigrh.sp.gov.br> Acesso em: nov. 2009.

SANSOLO, D.G.; BURSZTYN, I. Turismo de base comunitária: potencialidade no espaço rural brasileiro. In: BARTHOLO, R.; SANSOLO, D.G.; BURSZTYN, I. Turismo de Base Comunitária diversidade de olhares e experiências brasileiras. Rio de Janeiro: Editora Letra e imagem, 2009, parte I, p.142-161.

SAMPAIO, C. A. C. et al. Análise comparativa de experiências de turismo comunitário no Brasil e no Chile. Revista de Negócios, v.10, p. 288-301, 2005.

Secretaria de Turismo do Estado de Minas Gerais. Disponível em: http:// www.turismo.mg.gov.br/circuitos-turisticos/mapa/986-circuito-turistico-serras-de-

minas. Acessado em dezembro de 2011.

UNCTAD/WTO. Módulo de Treinamento para o Sucesso do Turismo Baseado na Comunidade - TBC no Âmbito do PRPE - Programa de Redução da pobreza através da Exportação. Internacional Trade Center - ITC. 96p. 2005.

WWF-BRASIL. Certificação em Turismo: Lições mundiais e recomendações para o Brasil. SALAZAR, Sergio (Coord.). Brasília: WWF Brasil, 2001.141p.

ZECHNER, T. C. In: II SEMINÁRIO INTERNACIONAL DE TURISMO SUSTENTÁVEL, Anais, 5, 2008, Fortaleza - CE.

ZECHNER, T. C. et al. Pensando o conceito de turismo comunitário a partir de experiências brasileiras, chilenas e costarriquenhas. Disponível em: http:// www.cdvhs.org.br/sispub/image-data/1893/sits/files/PENSANDO\%200\%

20CONCEITO\%20DE\%20TURISMO\%20COMUNITARIO.pdf. Acesso em dezembro de 2010.

\section{Agradecimentos:}

À Universidade Federal de Viçosa por me propiciar este estudo de doutorado, ao CNPq por me fornecer a bolsa de pesquisa e ao Ministério do Turismo por possibilitar acontecer o Projeto Boas Práticas do Turismo de Base Comunitária. 
Werter Valentim Moraes: Universidade Federal de Minas Gerais, Belo Horizonte, MG, Brasil.

Email:wvmoraes@hotmail.com

Link para o currículo Lattes: http://lattes.cnpq.br/9223383660522009

Guido Assunção Ribeiro: Universidade Federal de Viçosa, Viçosa, MG, Brasil.

Email: gribeiro@ufv.br

Link para o currículo Lattes: http://lattes.cnpq.br/9849187635825179

Data de submissão: 28 de maio de 2012

Data de recebimento de correções: 17 de setembro de 2012

Data do aceite: 19 de novembro de 2012

Avaliado anonimamente 